\title{
Advancing Children's Rights through the CRC: A Retrospective on the Work of the Society for Children and Youth of British Columbia
}

\author{
Jamie Neill \\ Society for Children and Youth of BC
}

\begin{abstract}
This article traces the gradual adoption of the United Nations Convention on the Rights of the Child as a framework for action by one of B.C. 's longstanding charitable organizations advancing the well-being of children and youth, the Society for Children and Youth of BC. Using the four guiding principles of the Convention as a lens, this retrospective examines how the Society's projects have been informed by, and benefited from, the Convention.

Since 1974, the Society for Children and Youth of BC has focused on providing a strong voice representing young people, as well as supporting adult duty bearers to improve the well-being of children and youth in British Columbia. Using the UN Convention on the Rights of the Child as a foundation, SCY has a track record of creating and delivering programs that have motivated change in research, legislation, policy, and practice in Canada. For more information please visit our website at: www.scyofbc.org
\end{abstract}

Keywords: Convention on the Rights of the Child, Society for Children and Youth of BC, children's rights, youth serving organizations

\section{Introduction}

The values that underlie children's rights have always been important to the Society for Children and Youth of BC (SCY). From its start over 40 years ago, its board members and staff have approached issues affecting children and youth from perspectives that recognize the 
importance of certain key principles to children's well-being. Equality, protection, self-worth concepts such as these formed the ideological motivation behind the organization's earliest research and advocacy in the 1970s with respect to the sexual exploitation of children and youth in British Columbia.

Over time, these values have taken on an even deeper importance for the Society, ushering in a transition from utilizing rights-centric concepts as a subtext for its projects to advancing children's rights as the explicit aim of the projects themselves. The point when this process began is rather easy to identify on SCY's timeline. It started in the early 1990s, shortly after the United Nations General Assembly's passage of the Convention on the Rights of the Child (CRC).

The CRC codified values into standards of behaviour, representing an international consensus on what childhood ought to be. Very importantly for the Society, these values mapped directly onto those of the organization. In fact, the importance of the CRC to SCY cannot be overstated. The framework the articles of the CRC provide enabled the organization to unify its disparate project streams and find new audiences with which to engage. But the transition was not made immediately. Over the years, the organization has increasingly emphasized the CRC as its foundational document. Today, from advocacy and community engagement to education, all facets of the Society's project work draw clearly upon the Convention.

This article traces the gradual adoption of the CRC as a framework for action by one of B.C.'s most prominent and longstanding organizations dedicated exclusively to the well-being of children and youth in the province. It also highlights the advantages this framework has provided SCY's project work.

\section{The Adoption of a Children's Rights Approach}

SCY has always enjoyed the strong leadership of its volunteer board members and of its various executive directors. This strong leadership is arguably attributable to two major factors: diversity and longevity. For the former, board members represent a broad range of child-serving sectors, including doctors, lawyers, teachers, social workers, and more. For the latter, many board members and directors stay for substantial lengths of time. In fact, the Society boasts multiple board members and an Executive Director who has stayed in the post for over two decades. 
The benefits arising from SCY's leadership are likewise twofold, and were deepened by the organization's respect for the CRC. First, the diversity of the board membership ensured that a diversity of projects could be undertaken simultaneously. For example, two of SCY's largest project streams occurring during the formulation of the $\mathrm{CRC}$ were on child abuse and on the importance of play as part of children's healthy development. The reliance on the CRC as a guide allowed SCY to situate both of these projects (and many others!) within the common framework of children's rights. Second, the long tenure of its board and staff has provided the organization with long-term vision and organizational memory. This has enabled SCY's multi-year projects to develop over time, and to become increasingly situated within the language of rights.

The volunteer board and the Executive Directors share a common vision of conceptualizing children, and childhood well-being, in a more holistic sense. Coupled with national and provincial interest towards the progressive realization of rights, SCY's holistic approach has led the organization to adopt a rights-based paradigm. By 1994, SCY explicitly promoted this paradigm with the start of the Rights Awareness Project (RAP).

The RAP's primary objectives were to promote the Convention, to increase public knowledge of the Convention, and to monitor compliance both in Canada and in British Columbia. However, the project itself had a profound effect on the organization's view of its own work. While earlier SCY initiatives had advanced elements of children's rights, RAP represented SCY's first attempt to specifically tie together its work on play, abuse and neglect, youth justice, and youth participation under the framework of the Convention. This structure mapped back to the organization's conception of a normative experience of childhood. The RAP began rather humbly; it began simply as a toolkit with resources and workshop materials on the above topic areas. Within a few short years, it was far more all-encompassing. By the late 1990s, the RAP had gone so far beyond the initial four topic areas that it was essentially the umbrella initiative for the majority of SCY's rights-based project work. The role and importance of the RAP to the organization continues to this day, as the project has progressed and evolved into SCY's Child Rights Public Awareness Campaign.

Tracing the development of SCY's projects pre- and post-RAP provides an interesting insight. This consideration may not have been the intention of the organization's leadership when the transition occurred, but is quite obvious in retrospect: namely, the work of the Society during this period can be categorized as broadly falling under the four guiding principles of the CRC. In 
other words, when examining the history of the organization, the work of SCY since the very early 1990s progressively drew upon Article 2 (non-discrimination and universal applicability of the Convention towards children), Article 3 (the best interests of the child should be the primary concern in all actions that concern the child), Article 6 (the right to life, survival, and development), and Article 12 (respect for the views of the child).

\section{The Four Guiding Principles and their Effect on the Work of SCY}

\section{Article 2: Non-discrimination}

Pressing government decision-makers on the non-discriminatory provision of services formed a key part of SCY's advocacy work in the early 1990s, as exemplified through SCY's response to the government white paper, Making Changes: Next Steps on the then-proposed Child, Family and Community Services Act. While the 1993 paper makes no overt reference to CRC Article 2, the principle is nevertheless present as the critique points out the lack of equitable support for Aboriginal communities in $\mathrm{BC}$.

A decade later, the principle of non-discrimination became much more prominent in SCY's project work. For example, the 2003 publication as part of the RAP, Perspectives on the Rights of Children with Disabilities, explicitly illustrates how the Convention could be used as a tool to advocate for greater respect for, and realization of, the rights of children with disabilities. It emphasizes the Convention's binding nature, its recognition of the important role of the family and of state support for the family, and most importantly, its framework for inclusion. Relying on CRC Article 2 and Article 23 (that is, special rights for children with disabilities), the publication argues that greater efforts put towards inclusion and equality of opportunity will have a profound effect on the creation of a more rights-respecting environment.

\section{Article 3: The best interests of the child}

Though all of SCY's work can be generally seen to fall under this principle, situating the best interests of the child within the rights-based context of the Convention has occurred somewhat more recently. In 1992, the Society prepared a brief to the Child Protection Legislation Review Panel as part of its review of the Family and Child Service Act, amid questions with respect to the utility of BC's legislative framework concerning child welfare. This 
brief provides a wide array of recommendations for legislative change, advancing more robust prevention strategies, and less intrusive interventions. It also highlights the need to make any new legislation reflect the best interests of the child, making reference to the CRC and Canada and BC's commitment to it.

By the late 1990s, the CRC was no longer on the periphery of SCY's legislative assessments and was now taking centre stage. In 1998, SCY released its multi-year review of domestic legislation as part of the key compliance-monitoring phase of RAP, The UN Convention on the Rights of the Child: Does Domestic Legislation Measure Up? This comprehensive review utilized a four-star rating system to assess the degree to which BC statutes complied with the Convention, weighing all relevant sections of the statutes against each article of the Convention. Though numerous articles are referenced as providing a framework through which to establish the star rating (particularly Article 12: the views of the child), the primary purpose of the project itself was to ensure that legislation upheld the best interests principle.

\section{Article 6: The right to life, survival and development}

As noted above, one of SCY's earliest major projects tackled the issue of child abuse. Since its inception, the Society had undertaken many projects addressing the surrounding challenges (including research, commenting on legislation and policy, critiquing and putting in place abuse prevention programs in schools, and opening a resource centre for professionals and the public), but the most long-lasting project was undoubtedly its newsletter. Circulated to several thousand recipients throughout the province on a quarterly basis, the newsletter was initially focused solely on child sexual abuse, later expanding to include child abuse and neglect more generally. By 1996, the newsletter was retitled to FOCUS on Children and Youth and became much more rights-centric, situating its discussion of abuse in the context of violations of children's protection rights under the $\mathrm{CRC}$. The reliance on the $\mathrm{CRC}$ as a framework also allowed the newsletter to widen its scope to address other issues.

One of the major benefits of the changed format was the potential for FOCUS to provide a venue for SCY to publicize and disseminate the position papers it had developed. Between 1984 and 2001, eight papers were prepared (primarily for lobbying purposes, though they found a strong audience within the general readership of the newsletter) on a wide range of issues. Indicative of the growing valuation of the rights-based framework within the organization, 
whereas the three publications (war toys, physical education, and poverty) made prior to 1994 made no reference to rights or to the Convention, the succeeding five publications (corporal punishment, youth justice, environmental tobacco, children and sport, and a child's right to play) drew on Article 6 (the right to life, survival, and development) and other articles to base their arguments.

Promoting the idea of children's free play as integral to their healthy development has been another longstanding area of interest to the organization. One project undertaken in support of this initiative was the opening of a Children's Play Resource Centre, which served as a clearinghouse on all aspects of play and sport from the mid-1980s until its closure in the early 2000s. SCY publications in support of free play included Focus on Children in 1991 and Making Space for Children in 1999. The latter of these is particularly significant as it draws upon the articles of the CRC, namely Article 31 (the right to play) and Article 6, specifically noting that play enhances every aspect of a child's development.

The project work on play was always highly cognizant of the need for appropriate environments for children's activities, and this environmental awareness eventually gave rise to additional areas of inquiry. Child Friendly Housing: A Guide for Housing Professionals was published by SCY in 1995, and was designed to inform professionals and decision-makers of children's needs within the housing sphere. While this project was a reaction to the increase in multi-family dwellings and considerations for children's needs, it made no overt reference to children's rights or to the Convention. When SCY presented this work at the Habitat II conference, the discussion that ensued resulted in the recognition that housing, while significant in children's lives, could not be addressed in isolation. As with the framework for children's rights, children's environments must be approached more holistically. This then became the Child and Youth Friendly Communities Initiative (CYFC) in 1999, which continues to this day.

The CYFC project placed children's rights in a much more overt role than the work on housing. Articles from the Convention, including support for parents and families, nondiscriminatory provision for services, safety and health, and child participation in decisionmaking, are referenced as guiding principles of the work. Significantly, the promotion of a child's rights to development was the foundation on which the research, publications, and calls to action relied. 


\section{Article 12: The Child's right to be heard and their views considered}

SCY's history of child and youth participation parallels that of the historical and cultural views of children of the day. At the time it was founded it was believed that children were best served by adults lobbying other adults on behalf of children and youth. This meant that incorporation of child and youth participation into the organization's rights-based work occurred later than some of the other guiding principles of the CRC. The development of the Rights Awareness Project illustrates this situation quite effectively.

As mentioned earlier, the Rights Awareness Project initially incorporated the issues of child abuse and neglect, youth justice, and play and recreation when it began in 1994. However, in 1995, following an initial survey on awareness of the Convention among child and youth serving organizations, SCY learned that it was looking at only one side of the problem. In other words, effectively promoting the Convention to the point that it would foster a change in the rights-respecting environment would require the help of the Convention's intended beneficiaries: the children themselves. The next phase of RAP thus worked to incorporate greater participation of young people by promoting awareness of the Convention to youth by youth, hiring two Youth Coordinators, and working in consultation with a Youth Advisory Committee.

RAP's focus on child and youth participation deepened even further in the succeeding years. In 2005, SCY worked to support youth to increase their knowledge of the CRC, and to report and analyze child rights issues of concern to them. This process was entirely youth-driven, with youth facilitators leading workshops for their peers throughout Vancouver. With the invaluable assistance of youth recorders documenting participants' personal stories of rights violations, the work was later compiled into Canada's first youth-led rights monitoring initiative, entitled A People's Project.

As noted above, the work of RAP evolved into the Child Rights Public Awareness Campaign. This initiative was undertaken in 2006 in partnership with the B.C. Representative for Children and Youth, University of the Fraser Valley Centre for Safe Schools and Communities, and ReelYouth, as well as a campaign advisory of representatives from child-serving organizations. The campaign seeks to change the attitudes and assumptions about children and their role in society held by adult duty bearers in the province, using the Convention as a foundation. The campaign makes extensive use of multi-media to reach its diverse audience, 
having created and disseminated numerous materials simplifying the language of the Convention and emphasizing key elements that promote child well-being within a rights-based context.

As the Child Rights Public Awareness Campaign evolved, a respectful way of including the view of children and youth in the messaging was sought. A radio public service announcement project was deemed an appropriate method of balancing the young people's rights to privacy and self-expression. Participants drew from their own lived experience and created powerful announcements designed to remind the adult duty bearers of their responsibilities in upholding children's rights. More recently, SCY has been involved with community planning tables, assisting them with the same balancing act: involving children in meaningful, respectful, and safe methods of sharing their views.

\section{The CRC and SCY Today}

While we celebrate the $25^{\text {th }}$ anniversary of the $\mathrm{CRC}$, now more than ever, a rights-centric approach to improving the lives of children and youth is crucial. In BC, young people face the highest rate of poverty of any province in Canada (nearly one in five), continued cuts to education, and the complete cessation of government support for those in care as they age out of the system at 19 . For new parents, affordable early childhood education spaces are extremely limited. Over $30 \%$ of our youngest citizens are starting kindergarten vulnerable in one or more areas of development. Funding for the health, social welfare, and education of First Nations children on reserves is below many of the provincial standards.

Since BC's ratification of the CRC over two decades ago, the Society for Children and Youth of $\mathrm{BC}$ has been using the Convention to tackle issues such as those listed above. Today, SCY's two major project streams, the Child and Youth Friendly Communities project, and the Child Rights Public Awareness campaign, continue to advance the holistic approach to child development begun forty years ago. Whether it is through engaging with decision makers, spreading the message of rights to new audiences, or serving as a clearinghouse for information on children's rights, the CRC provides SCY with a complete roadmap of where BC (and Canada) needs to be to ensure all children develop to their fullest potential. 